\title{
Clinical characteristic of prodromal symptoms between bipolar I and II disorder among Chinese patients: a retrospective study
}

Qian Zhao ${ }^{1,2 \dagger}$, Tong Guo ${ }^{1 \dagger}$, Yang $\mathrm{Li}^{1+}$, Lei Zhang ${ }^{1}$, Nan Lyu ${ }^{1}$, Amanda Wilson ${ }^{3}$, Xuequan Zhu ${ }^{1,2}$ and Xiaohong $\mathrm{Li}^{1^{*}}$

\begin{abstract}
Background: This study aimed to identify the clinical characteristic of prodromal symptoms in Chinese patients with bipolar disorder (BD), prior to the first affective episode. It further aimed to characterize the prodromal traits between bipolar disorder type I (BD-I) and type II (BD-II).

Methods: 120 individuals with BD-I $(n=92)$ and BD- II $(n=28)$ were recruited to the study. Semi-structured interviews were then administered to evaluate prodromal symptoms in patients, within 3 years of BD onset, by using the Bipolar Prodrome Symptom Scale-Retrospective (BPSS-R).

Results: In the prodromal phase of the first depressive episode, patients with BD-\|l experienced more prodromal symptoms ( $p=0.0028$ ) compared to BD-I. Additionally, more frequent predictors were reported in patients with BDII than BD-I including educational and occupational dysfunction $(p=0.0023)$, social isolation $(p<0.001)$, difficulty making decisions $(p=0.0012)$, oppositionality $(p=0.012)$, and suspiciousness/persecutory ideas $(p=0.017)$. There were also differences in the duration of the precursors. The duration of "weight loss or decrease in appetite" ( $p=$ $0.016)$ lasted longer in patients with BD-I, while "obsessions and compulsions" ( $p=0.023)$ started earlier in patients with BD-II and occurred during the pre-depressive period. The prevalence and duration of each reported prodrome, preceding a first (hypo) manic episode, showed no difference between patients with BD-I and BD-II.

Conclusions: Specific affective, general, or psychotic symptoms occurred prior to both affective episodes. The characteristic of prodromal symptoms were key predictors for later episodes of BD including attenuated mania-like symptoms, subthreshold depressed mood, mood swings/lability, and anxiety. In the pre-depressive state, when compared to BD-II, BD-I presented with more prodromal symptoms in nonspecific dimensions, which indicated the substantial burden of BD-II. In conclusion, this study extends the understanding of the characteristics of prodromes of BD-I and BD-II.
\end{abstract}

Keywords: Bipolar II disorder, Bipolar I disorder, Prodromal symptoms, Early recognition, Depression, Mania

\footnotetext{
*Correspondence: lixiaohong_anding@ccmu.edu.cn;

lixishouyi2003@hotmail.com

${ }^{\dagger}$ Qian Zhao, Tong Guo and Yang Li contributed equally to this work.

'The National Clinical Research Center for Mental Disorders \& Beijing Key

Laboratory of Mental Disorders, Beijing Anding Hospital, Capital Medical University, Beijing, China

Full list of author information is available at the end of the article
}

(c) The Author(s). 2021 Open Access This article is licensed under a Creative Commons Attribution 4.0 International License, which permits use, sharing, adaptation, distribution and reproduction in any medium or format, as long as you give appropriate credit to the original author(s) and the source, provide a link to the Creative Commons licence, and indicate if changes were made. The images or other third party material in this article are included in the article's Creative Commons licence, unless indicated otherwise in a credit line to the material. If material is not included in the article's Creative Commons licence and your intended use is not permitted by statutory regulation or exceeds the permitted use, you will need to obtain permission directly from the copyright holder. To view a copy of this licence, visit http://creativecommons.org/licenses/by/4.0/ The Creative Commons Public Domain Dedication waiver (http://creativecommons.org/publicdomain/zero/1.0/) applies to the data made available in this article, unless otherwise stated in a credit line to the data. 


\section{Background}

Bipolar disorder (BD) is a common, chronic, and highly morbid disorder characterized by affective lability, which often runs a relapsing and remitting course, affecting 2$3 \%$ of the general population worldwide [1, 2]. The diversity of $\mathrm{BD}$ lies in the many forms of the disorder, including, depressive and manic or hypomanic episodes, mixed emotional states, rapid cycling, and psychosis between episodes. Patients vary greatly in the severity of their symptoms, the duration of episodes, the number of episodes, the degree of recovery between episodes, and the pattern of polarity $[3,4]$. Due to the complexity of the clinical presentation of $\mathrm{BD}$, there is a significant delay in diagnosis. Therefore, early recognition and intervention are important to improve the prognosis, provide intervention, and decreases the burden of the disorder.

Current evidence suggests that $\mathrm{BD}$ has a progressive nature [5-7], therefore supporting the theory that milder phases of the condition gradually progress to the full onset of the disorder [8]. The milder phases include the emergence of prodromal symptoms, which are symptoms and signs prior to episode onset; these symptoms are considered an ideal intervention state, as patients in early stages are more likely to be responsive to treatment and therefore may need less complex interventions $[9,10]$. For this reason, the identification of risk factors, or prodromal symptoms, are important and have received increasing attention from researchers. In particular, disruptive behavior disorders, major depressive episodes, and subthreshold manic episodes were all associated with the development of BD among at-risk youth in the Pittsburgh Bipolar Offspring Study (BIOS) [11]. Anxiety/depression, affective lability, and subsyndromal manic symptoms were further established to be the strongest predictors of $\mathrm{BD}$ in the study [12]. In a longitudinal study with 107 Dutch adolescent who were bipolar offspring, again subthreshold manic experiences were confirmed to be the strongest predictor of $\mathrm{BD}$ conversion and depressive symptoms were considered to be a significant predictor for the onset of the first mood related episode [13].

Risk factors contribute to identify individuals at high risk of conversion to BD. Having a family history of BD is one of the widely recognized risk factors. Previous studies have established that the children of parents who have early-onset BD probands, also have an increased risk of BD in adulthood [12, 14]. Furthermore, research has identified that an earlier age of onset for depression, the presence of psychotic symptoms, and functional impairment robustly predicting factors of conversion [15, 16]. Environmental factors, such as life events [17], lifetime sexual abuse [18] and substance misuse [19], also play a role in defining the risk stage implicated in prodromal signs.

Most studies of the BD prodromes have used unstructured questionnaires or chart reviews and have not evaluated onset patterns systematically. The Bipolar Prodrome Symptom Scale-Retrospective (BPSS-R), is a promising screening tool to assess behavioral and symptomatic changes using semi-structured interviews [20]. Studies that have completed a detailed evaluation using the BPSS-R show that mood swings were a precursor, evolving into subthreshold (hypo) manic symptoms of subsequent BD [21]. A further study also revealed that the development of symptoms, prior to a first manic episode, were gradual in the majority of patients $(88.5 \%)$, with the mean duration of progression being $10.3 \pm 14.4$ months. Additionally, more than half of the youth reported to have subthreshold manic symptoms, decreased school/work functioning, mood swings, and depressed mood [22]. By using a combination of the temperament scales and BPSS-R scale [23], cyclothymic temperament was found to be a significant factor to identify people atrisk of developing BD-I and -II, which may contribute to an increase in the predictive validity of prodromal symptoms.

BD-I and BD- II are the most common subtypes of BD. They vary considerably, with differences in symptomatology, management, and prognosis. Some studies revealed that BD-II when compared to BD-I presented with more severe depressive episodes, more comorbidity with anxiety disorders, and a greater risk of suicide attempts [24]. Several features associated with BD-I include greater atypical symptoms, prevalence of psychotic symptoms during a depressive episodes [25], and a greater number of annual shifts in symptom polarity [26]. These differences between BD-I and-II may begin very early in the disorder and even present as predictors for different types of $\mathrm{BD}$, which are differences that require further exploration.

In consideration of the importance of prodromal symptoms for early intervention and variability between $\mathrm{BD}-\mathrm{I}$ and BD-II, the researchers conducted a retrospective study to identify prodromal symptoms in patients with $\mathrm{BD}$ prior to the first full depressive and the first hypo/manic episode. The study was conducted with Chinese patients and further characterized the prodromal traits, in detail, between BD-I and BD-II patients.

\section{Material and methods Study design}

This retrospective study enrolled 120 Chinese patients with BD, including 92 with BD-I and 28 with BD-II. Participants were recruited from Beijing Anding Hospital, a University affiliated teaching hospital in China. All 
participants completed the BPSS-R. The researchers explored clinical characteristic of prodromal symptoms in patients with bipolar disorder (BD), prior to the first affective episode, and further compared the prodromal traits between bipolar disorder type I (BD-I) and type II (BD-II).

\section{Study sample}

All participants completed the clinical interview, and met the inclusion criteria, which was: 1) diagnosis of BD; 2) in clinical remission from $\mathrm{BD} ; 3$ ) the first (hypo) manic episode was within three years of the research study. The clinical status and evaluations of participants were validated by two of the senior attending psychiatrists from the hospital. The Chinese Structured Clinical Interview for Diagnostic and Statistical Manual (DSM)IV-TR axis 1 disorders (SCID) was used to confirm a BD diagnosis [27]. A standardized questionnaire was designed to collect demographic data. The Hamilton Depression Scale-17 (HAMD-17) [28, 29] and the Young Mania Rating Scale (YMRS) [30] were used to rate symptom severity. The current remission status of participants was confirmed by the HAMD-17, including those with a score less than 17, and the YMRS, including those with a score less than 12. The BPSS-R interview was conducted by a trained psychiatrist with all participants to both trace and assess prodromal symptoms prior to a first depressive or (hypo) maniac episode. As the study included patients with BD-II as well, the prodromal symptoms prior to a first manic and hypomanic episode were merged for BD-II patients. Those who had drug or alcohol dependence or substance use issues within the last year, had a history of stroke, a head injury, had epilepsy, and/or had a presence of progressive systemic disorders were excluded from participation.

\section{Instruments}

BPSS-R is a semi-structured interview instrument, which was designed based on the severity of downward criteria in the DSM-IV, it is based on available diagnostic and psychopathology assessment scales for $\mathrm{BD}$ and major depressive disorder (MDD). Consent was obtained to use the scale from Correll [20], the author of the original scale. In order to avoid the potential impact of cultural differences, the researchers used a back-translation method. The scale was translated into Chinese by one translator and then translated back into English again by an independent translator who was blind to the original scale. The back-translation version had the same meaning as the original, which ensured the adaption was culturally relevant and in a comprehensible form for Chinese psychiatrists and patients, while at the same time replicable of the original scale.
The BPSS- $\mathrm{R}$ assesses the onset pattern, duration, severity, and frequency of 39 symptoms and signs that emerge or become worse prior to the first (hypo) manic or major depressive episode. Prodromal symptom severity is divided into 3 levels $(1=$ mild, $2=$ moderate, and $3=$ severe). Symptom frequency is divided into 4 levels ( $1=$ rarely, 2 = relapse/intermittent, $3=$ continuous, and $4=$ lifetime/ personality). The pre-onset symptoms are categorized into four subgroups: mania index (extremely energetic/active; overly cheerful, happy, on top of the world; racing thoughts; overly talkative; decreased need for sleep; irritability or anger; overly self-confident; trouble concentrating; physically agitated; increased sexual energy; reckless or dangerous behavior; risky sexual behavior); depression index (depressed mood; tiredness or lack of energy; reduction of enjoyment/ interest; trouble concentrating; insomnia; feeling of worthlessness or guilt; weight loss or decrease in appetite; slow movement; suicidality; physical agitation; sleeping too much; attempting suicide; weight gain or increasing in appetite); general index (educational and occupational dysfunction; anxiety or nervousness; social isolation; frequent mood swings/lability; difficulty making decisions; obsessions and compulsions; losing temper frequently or trouble controlling anger; day/night sleep reversal; self-injurious behavior; oppositionality; giddy, clownish; increased creativity); and psychosis index (suspiciousness/persecutory ideas; strange or unusual ideas; difficulty thinking or communicating clearly; hallucinations).

\section{Data analysis}

All data were analyzed using SAS 9.4 for Windows. The Shapiro-Wilk Test was used to check normality in data distribution. Continuous variables were analyzed by an Independent Sample t-Test for normal distribution. Continuous variables that lacked normal distribution and presented with variance and non-homogeneity were analyzed using the Wilcoxon (Mann-Whitney U) Rank Sum Test. Continuous data were described using mean and standard deviation. Categorical data was indicated by number and percentage (\%) and were then compared by the Chi-square Test or Fisher Exact Probability Test between the two groups. A two-tailed $p$-value was utilized for various statistical analyses, and $p<0.05$ was considered to be statistically significant.

\section{Results}

\section{Study population}

Demographic and clinical characteristics of the 120 patients with $\mathrm{BD}$ are summarized in Table $1.76 .7 \%$ of patients were diagnosed with BD-I, 23.3\% with BD-II. 65\% of participants were male and the mean age was 26.5 years old $(S D=10.0)$. Average years of schooling were 
Table 1 Demographic Characteristics and Disorder Characteristics of BD Patients

\begin{tabular}{|c|c|c|c|c|c|}
\hline Variables & Total $(n=120)$ & $\begin{array}{l}\text { BD-I } \\
(n=92)\end{array}$ & $\mathrm{BD}-\mathrm{II}(n=28)$ & $t / x^{2}$ & $P$-value \\
\hline Age (years, mean $\pm S D$ ) & $26.5 \pm 10.0$ & $27.4 \pm 10.4$ & $24.7 \pm 8.4$ & 1.26 & 0.21 \\
\hline Male sex $(n, \%)$ & $78(65.0 \%)$ & $61(66.3 \%)$ & $17(60.7 \%)$ & 0.29 & 0.59 \\
\hline Education (years, mean \pm SD) & $12.3 \pm 3.3$ & $12.4 \pm 3.3$ & $12.3 \pm 3.3$ & 0.15 & 0.89 \\
\hline \multicolumn{6}{|l|}{ Marital status (n, \%) } \\
\hline Unmarried & $75(62.5 \%)$ & $54(58.7 \%)$ & $21(75.0 \%)$ & 2.43 & 0.12 \\
\hline Married/ Divorced/other & $45(37.5 \%)$ & $38(41.3 \%)$ & $7(25.0 \%)$ & & \\
\hline Age at first episode (years, mean $\pm S D$ ) & $25.6 \pm 10.2$ & $26.3 \pm 10.6$ & $23.1 \pm 8.7$ & 1.47 & 0.14 \\
\hline Age at first clinical visit (years, mean \pm SD) & $26.2 \pm 10.2$ & $26.8 \pm 10.6$ & $23.9 \pm 8.4$ & 1.59 & 0.17 \\
\hline Lag between first episode and clinical visit (months, mean \pm SD) & $7.2 \pm 12.6$ & $6.8 \pm 10.0$ & $10.8 \pm 16.7$ & 0.20 & 0.65 \\
\hline Disorder course (months, mean \pm SD) & $20.3 \pm 15.7$ & $19.4 \pm 16.3$ & $23.1 \pm 13.7$ & $2.90^{*}$ & 0.089 \\
\hline \multicolumn{6}{|l|}{ Remission ( $\mathrm{n}, \%)$} \\
\hline Partial remission & $68(56.7 \%)$ & $53(58.2 \%)$ & $15(53.6 \%)$ & 0.1907 & 0.66 \\
\hline Full remission & $52(43.3 \%)$ & $39(42.4 \%)$ & $13(46.4 \%)$ & & \\
\hline vTotal scores of HAMD-17 (mean \pm SD) & $1.4 \pm 1.9$ & $1.3 \pm 1.8$ & $1.8 \pm 2.2$ & $0.90^{*}$ & 0.34 \\
\hline Total scores of YMRS (mean \pm SD) & $0.7 \pm 1.1$ & $0.7 \pm 1.2$ & $0.4 \pm 1.4$ & 3.8472 & 0.05 \\
\hline
\end{tabular}

Abbreviations: BD, Bipolar Disorder; SD, Standard Deviation; HAMD-17, The Hamilton Depression Scale17; YMRS, Young Mania Rating Scale

12.3 years $(\mathrm{SD}=3.3)$ and more than half $(62.5 \%)$ of the participants were unmarried. The mean age at first episode was 26.3 years old $(\mathrm{SD}=10.6)$ in BD-I and 23.1 years old $(\mathrm{SD}=8.7)$ in $\mathrm{BD}$-II patients. The mean age at the first episode was $25.6(\mathrm{SD}=10.2)$ and the average age to seek medical aid was $26.2(\mathrm{SD}=10.2)$. In addition, the substantial lag between onset of the disorder and clinical intervention was more than half a year $(7.2 \pm$ 12.6 months).

The disorder cause, defined as the period from the date of first BD-I and BD-II diagnosis to the time of the interview was 20.3 months ( $S D=15.7)$. The lag in presentation and disorder onset was longer in patients with BD-II than BD-I $(10.8 \pm 16.7$ months vs. $6.8 \pm 10.0$ months; $23.1 \pm 13.7$ months vs. $19.4 \pm 16.3$ months), although it was not statistical significance. $58.2 \%$ of patients with BD-I and $53.6 \%$ of patients with BD-II achieved partial remission. The average of total scores of HAMD-17 and YMRS were low, 1.4 $(\mathrm{SD}=1.9)$ and 0.7 $(\mathrm{SD}=1.1)$ respectively, which was in accordance with the enrollment criteria (current absence of major manic or depressive symptoms). Participants who achieved full remission were $42.9 \%$ in $\mathrm{BD}-\mathrm{I}$ and $41.8 \%$ in $\mathrm{BD}-\mathrm{II}$ groups. Overall, demographic characters and clinical variables showed no differences between BD-I and BD-II patients.

In patients with BD-I, there were $67.4 \%(62 / 92)$ and 94.6\% (87/92) of patients reporting prodromal symptoms prior to the first depressive episode and the first manic episode respectively. In patients with BD-II, 78.6\% (22/ $28)$ and $92.2 \%(26 / 28)$ of patients reported prodromal symptoms prior to the first depressive episode and the first hypomanic episode. Most symptoms in the prodromal state were reported to persist through the first full-brown affective episode and specific symptom items are shown in Supplementary Table 1 and Supplementary Table 2. All patients who reported at least one symptom belonging to the subgroup domains were considered in each index's total score.

\section{Prodromal symptoms prior to the fist depressive episode Prevalence}

The prevalence of prodromal symptoms between patients with BD-I and BD-II prior to first depressive episode are displayed in Table 2. 54.4\% patients with BD-I and $85.7 \%$ of patients with BD-II reported early manifestations prior to a first full depressive episode, and more BD-II patients experienced prodromal symptoms in this study $(p=0.0028)$. Although the proportion of the presence of each item in the depressive index showed no difference between BD-I and BD-II groups, the depressive index total was detected to have a significant difference between BD-I and BD-II groups $(p=0.0063)$. Most patients $(53.3 \%$ for BD-I and $82.1 \%$ for BD-II) reported depression-related symptoms in the prodromal phase of the first depressive episode. The five most frequent prodromal symptoms in the depressive index in BD patients were "depressed mood" (BD-I: 40.2\%, BD-II: 46.4\%), "reduction of enjoyment/ interest" (30.4\% for BD-I, 32.1\% for BD-II), "tiredness or lack of energy" (BD-I: 26.1\%, BD-II: 35.7\%), "trouble concentrating" (BD-I: 23.9\%, BDII: 42.9\%), and "insomnia" (BD-I: 21.7\%, BD-II: 39.3\%).

Prior to the first depressive episode, the prevalence of mania index total differed between patients with BD-I 
Table 2 Reported Prevalence and Duration of Prodromal Symptoms between Patients with BD-I and BD-II Prior to First Depressive Episode

\begin{tabular}{|c|c|c|c|c|c|c|c|c|c|c|}
\hline \multirow[t]{3}{*}{ Prodromal Symptom characteristics } & \multicolumn{5}{|c|}{ Prevalence (Yes) } & \multicolumn{5}{|c|}{ Duration (Weeks) } \\
\hline & \multicolumn{2}{|c|}{$\mathrm{BD}-\mathrm{I}(n=92)$} & \multicolumn{2}{|c|}{$\mathrm{BD}-\mathrm{II}(n=28)$} & \multirow[t]{2}{*}{$P$ value } & \multicolumn{2}{|c|}{$\mathrm{BD}-\mathrm{I}(n=92)$} & \multicolumn{2}{|c|}{$\mathrm{BD}-\mathrm{II}(n=28)$} & \multirow[t]{2}{*}{$P$ value } \\
\hline & $\mathrm{N}$ & $\%$ & N & $\%$ & & Mean & SD & Mean & SD & \\
\hline \multicolumn{11}{|l|}{ Mania Symptom Index } \\
\hline Extremely energetic/active & 3 & 3.3 & 1 & 3.6 & $1.00 \mathrm{a}$ & 8.6 & 0.0 & 0.0 & 0.0 & n.a. \\
\hline Overly cheerful, happy, on top of the world & 3 & 3.3 & 0 & 0.0 & $1.00 \mathrm{a}$ & 10.1 & 5.0 & 0.0 & 0.0 & n.a. \\
\hline Racing thoughts & 2 & 2.2 & 0 & 0.0 & $1.00 \mathrm{a}$ & 32.4 & 27.5 & 25.9 & 0.0 & 1.00 \\
\hline Overly talkative & 3 & 3.3 & 3 & 10.7 & $0.14 a$ & 13.0 & 0.0 & 25.9 & 24.4 & 1.00 \\
\hline Decreased need for sleep & 2 & 2.2 & 2 & 7.1 & $0.23 a$ & 0.0 & 0.0 & 0.0 & 0.0 & n.a. \\
\hline Irritability or anger & 11 & 12.0 & 6 & 21.4 & 0.22 & 11.7 & 9.1 & 5.4 & 3.1 & 0.14 \\
\hline Overly self-confident & 1 & 1.1 & 1 & 3.6 & 0.41 & 17.3 & 0.0 & 43.2 & 0.0 & 0.19 \\
\hline Physical agitated & 2 & 2.2 & 0 & 0.0 & $1.00 \mathrm{a}$ & 10.8 & 10.3 & 4.3 & 0.0 & 0.062 \\
\hline Increased sexual energy & 0 & 0.0 & 1 & 3.6 & $0.23 a$ & 4.3 & 0.0 & 43.2 & 0.0 & n.a. \\
\hline Reckless or dangerous behaviors & 0 & 0.0 & 0 & 0.0 & n.a. & 0.0 & 0.0 & 0.0 & 0.0 & n.a. \\
\hline Risky sexual behavior & 0 & 0.0 & 0 & 0.0 & n.a. & 0.0 & 0.0 & 0.0 & 0.0 & n.a. \\
\hline Trouble concentrating & 22 & 23.9 & 12 & 42.9 & 0.05 & 13.9 & 12.9 & 11.8 & 14.9 & 0.52 \\
\hline Mania Index total & 29 & 31.5 & 16 & 57.1 & $0.014^{*}$ & & & & & \\
\hline \multicolumn{11}{|l|}{ Depression Symptom Index } \\
\hline Depressed mood & 37 & 40.2 & 13 & 46.4 & 0.56 & 14.4 & 14.0 & 7.0 & 3.8 & 0.062 \\
\hline Tiredness or lack of energy & 24 & 26.1 & 10 & 35.7 & 0.32 & 12.3 & 10.2 & 6.7 & 3.0 & 0.11 \\
\hline Reduction of enjoyment/ interest & 28 & 30.4 & 9 & 32.1 & 0.90 & 15.4 & 16.7 & 7.9 & 6.6 & 0.21 \\
\hline Trouble concentrating & 22 & 23.9 & 12 & 42.9 & 0.05 & 13.9 & 12.9 & 11.8 & 14.9 & 0.52 \\
\hline Insomnia & 20 & 21.7 & 11 & 39.3 & 0.06 & 15.4 & 14.9 & 12.2 & 13.6 & 0.55 \\
\hline Feeling of worthlessness or guilt & 11 & 12.0 & 7 & 25.0 & $0.13^{\mathrm{a}}$ & 9.6 & 7.5 & 9.2 & 7.5 & 1.00 \\
\hline Weight loss or decrease in appetite & 8 & 8.7 & 5 & 17.9 & 0.18 & 17.3 & 16.2 & 5.6 & 3.3 & $0.016^{*}$ \\
\hline Physically slowed down & 6 & 6.5 & 5 & 17.9 & $0.13^{\mathrm{a}}$ & 9.2 & 9.1 & 4.3 & 0.0 & 0.36 \\
\hline Thinking about suicide & 6 & 6.5 & 3 & 10.7 & 0.43 & 8.0 & 8.1 & 10.8 & 3.1 & 0.15 \\
\hline Sleeping too much & 8 & 8.7 & 5 & 17.9 & 0.18 & 6.5 & 4.3 & 17.3 & 23.1 & 0.51 \\
\hline Attempting suicide & 3 & 3.3 & 2 & 7.1 & $0.33^{a}$ & 4.3 & 0.0 & 4.3 & 0.0 & 1.00 \\
\hline Weight gain or increasing in appetite & 4 & 4.4 & 1 & 3.6 & $1.00^{\mathrm{a}}$ & 23.3 & 18.0 & 23.8 & 27.5 & 0.85 \\
\hline Depression Index Total & 49 & 53.3 & 23 & 82.1 & $0.0063^{* *}$ & & & & & \\
\hline \multicolumn{11}{|l|}{ General Symptom Index } \\
\hline Educational and occupational dysfunction & 19 & 20.7 & 14 & 50.0 & $0.0023^{* *}$ & 9.7 & 8.2 & 4.3 & 0.0 & 0.27 \\
\hline Anxiety or nervousness & 24 & 26.1 & 11 & 39.3 & 0.18 & 13.2 & 12.6 & 11.8 & 13.8 & 0.74 \\
\hline Social Isolation & 14 & 15.2 & 15 & 53.6 & $<0.001^{* * *}$ & 4.3 & 0.0 & 0.0 & 0.0 & n.a. \\
\hline Frequent mood swings/lability & 10 & $10 / 9$ & 5 & 17.9 & $0.34 \mathrm{a}$ & 14.4 & 15.4 & 6.5 & 4.6 & 0.054 \\
\hline Difficulty making decisions & 6 & 6.5 & 9 & 32.1 & $0.0012 * *^{a}$ & 11.5 & 9.9 & 11.0 & 12.6 & 0.88 \\
\hline Obsessions and compulsions & 5 & 5.4 & 5 & 17.9 & $0.05^{a}$ & 6.9 & 3.9 & 21.6 & 14.5 & $0.023^{*}$ \\
\hline Losing temper frequently or trouble controlling anger & 9 & 9.8 & 2 & 7.1 & $1.00 \mathrm{a}$ & 11.5 & 8.5 & 8.6 & 7.5 & 0.4962 \\
\hline Day/night sleep reversal & 3 & 3.3 & 2 & 7.1 & $0.33 a$ & 13.7 & 15.3 & 25.9 & 24.1 & 0.3452 \\
\hline Self-injurious behavior (no intent to kill self) & 3 & 3.3 & 2 & 7.1 & 0.33 & 8.6 & 6.1 & 5.8 & 2.5 & 0.5541 \\
\hline Oppositionality & 0 & 0.0 & 3 & 10.7 & $0.012^{\mathrm{a}}$ & 5.8 & 2.5 & 4.3 & 0.0 & \\
\hline Giddy, clownish & 2 & 2.2 & 1 & 3.6 & $0.55^{a}$ & 0.0 & 0.0 & 19.4 & 21.4 & n.a. \\
\hline Increased creativity & 3 & 3.3 & 1 & 3.6 & $1.00^{\mathrm{a}}$ & 4.3 & 0.0 & 8.6 & 0.0 & n.a. \\
\hline
\end{tabular}


Table 2 Reported Prevalence and Duration of Prodromal Symptoms between Patients with BD-I and BD-II Prior to First Depressive Episode (Continued)

\begin{tabular}{|c|c|c|c|c|c|c|c|c|c|c|}
\hline \multirow{3}{*}{$\begin{array}{l}\text { Prodromal Symptom characteristics } \\
\text { General Index Total }\end{array}$} & \multicolumn{5}{|c|}{ Prevalence (Yes) } & \multicolumn{5}{|c|}{ Duration (Weeks) } \\
\hline & \multicolumn{2}{|c|}{$\mathrm{BD}-\mathrm{I}(n=92)$} & \multicolumn{2}{|c|}{$\mathrm{BD}-\mathrm{II}(n=28)$} & \multirow{2}{*}{$\frac{P \text { value }}{0.0008^{* * *}}$} & \multicolumn{2}{|c|}{$\mathrm{BD}-\mathrm{I}(n=92)$} & \multicolumn{2}{|c|}{ BD-II $(n=28)$} & \multirow[t]{2}{*}{$P$ value } \\
\hline & 39 & 42.4 & 22 & 78.6 & & & & & & \\
\hline \multicolumn{11}{|l|}{ Psychosis Symptom Index } \\
\hline Suspiciousness/persecutory ideas & 3 & 3.3 & 5 & 17.9 & $0.017^{*}$ & 4.3 & 0.0 & 7.6 & 6.5 & n.a. \\
\hline Strange or unusual ideas & 5 & 5.4 & 1 & 3.6 & $1.00^{a}$ & 30.3 & 30.6 & 23.8 & 27.5 & \\
\hline Difficulty thinking or communicating clearly & 17 & 18.5 & 7 & 25.0 & 0.45 & 10.9 & 8.6 & 5.9 & 4.0 & \\
\hline Hallucinations & 3 & 3.3 & 0 & 0.0 & $1.00^{\mathrm{a}}$ & 0.0 & 0.0 & 0.0 & 0.0 & n.a. \\
\hline Psychosis Index Total & 21 & 22.8 & 11 & 39.3 & 0.085 & & & & & \\
\hline BPSS-R Total & 50 & 54.4 & 24 & 85.7 & 0.0028 & & & & & \\
\hline
\end{tabular}

Abbreviations: BD, Bipolar Disorder; SD, Standard Deviation; BPSS-R, Bipolar Prodrome Symptom Scale-Retrospective

n.a. $=$ not applicable

${ }^{*} P<0.05 * * P<0.01{ }^{* * *} P<0.001$

a: Fisher exact test

and BD-II $(p=0.014)$. Although each item in the mania symptom index showed no statistical difference between the two BD groups, some items deserve attention. The item of "irritability or anger" and "overly talkative" tended to occurr more in BD-II group $(21.4 \% ; 10.7 \%)$.

The prevalence for the general symptom index total was significantly different during the depressive prodromal phase between the two BD groups (BD-I: $42.4 \%$ vs. BD-II: $78.6 \%, p<0.001)$. Four self-reported items of the general index, namely educational and occupational dysfunction $(p=0.0023)$, social isolation $(p<0.001)$, difficulty making decisions $(p=0.0012)$ and oppositionality $(p=0.012)$, were reported to occur significantly more often in BD-II patients, prior to the first depressive episode. Although, psychotic symptoms were not specific in $\mathrm{BD}$, the frequency of occurrence of suspiciousness/persecutory ideas was significantly higher in BD- II patients (17.9\%) than BD-I patients (3.3\%) during the predepressed phase $(p=0.017)$.

\section{Duration}

The comparison of the duration of prodromal symptoms prior to the fist depressive episode between BD-I and BD- II patients is shown in Table 2. The duration of each item during the manic and psychotic index symptoms did not differ significantly between the two BD groups. The symptom of "weight loss or decrease in appetite" in the depressive symptom index started significantly earlier and before the first full depressive episode among BD-I patients compared to BD- II patients $(17.3 \pm 16.2$ weeks vs. $5.6 \pm 3.3$ weeks, $p=0.016)$. The duration of "obsessions and compulsions" in the general symptom index in the pre-depressive stage was reported to last longer in BD- II patients than in BD-I patients. (21.6 \pm 14.5 weeks vs. $6.9 \pm 3.9$ weeks, $p=0.023)$.
Prodromal symptoms prior to the first (hypo) mania episode

\section{Prevalence and duration}

The results of reported prevalence and duration of prodromal symptoms between patients with BD-I and BD-II prior to the first (hypo) mania episode are shown in Table 3. $81.5 \%$ of patients with BD-I and $78.6 \%$ of patients with BD-II reported early manifestations prior to the first (hypo) manic episode. There was no significant difference between BD-I and BD-II patients in the presence of each item in the four dimensions; namely mania index, depression index, general index, and psychosis index. Reported prodromal symptoms with a prevalence of more than $25 \%$ included: "extremely energetic/active" (BD-I: 34.8\%, BD-II: 39.3\%), "overly cheerful, happy, on top of the word" (BD-I: 29.4\%, BD-II: 28.6\%), "racing thoughts" (BD-I: 26.1\%, BD-II: 21.4\%), "overly talkative" (BD-I: 34.8\%, BD-II: 32.1\%), "frequent mood swings/lability" (BD-I: 30.4\%, BD-II: 21.4\%), and "losing temper frequently or trouble controlling anger" (BD-I: 32.6\%, BD-II: 14.3\%). The duration of each prodromal symptom prior to the first (hypo) manic episode presented with no difference between BD-I and BD-II groups.

\section{Discussion}

To the researchers' knowledge, this is the first applied study of the BPSS-R among Chinese patients with BD to identify prodromal symptoms prior to first full affective episode. As well as being the first study to explore the prodromal differences between BD-I and BD-II patients, which has received little attention previously. In the prodromal phase of the first depressive episode, patients with BD-II experienced more prodromal symptoms ( $p=$ 0.0028) compared to BD-I. In patients with BD-II more frequent predictors included educational and occupational dysfunction $(p=0.0023)$, social isolation $(p<$ 
Table 3 Reported Prevalence and Duration of Prodromal Symptoms Between Patients with BD-I and BD-II Prior to the First Mania/ Hypomania Episode

\begin{tabular}{|c|c|c|c|c|c|c|c|c|c|c|}
\hline \multirow[t]{3}{*}{ Prodromal symptom characteristics } & \multicolumn{5}{|c|}{ Prevalence (Yes/No) } & \multicolumn{5}{|c|}{ Duration (Weeks) } \\
\hline & \multicolumn{2}{|c|}{$\mathrm{BD}-\mathrm{I}(n=92)$} & \multicolumn{2}{|c|}{$\mathrm{BD}-\mathrm{II}(n=28)$} & \multirow[t]{2}{*}{$P$ value } & \multicolumn{2}{|c|}{$\mathrm{BD}-\mathrm{I}(n=92)$} & \multicolumn{2}{|c|}{$\mathrm{BD}-\mathrm{II}(n=28)$} & \multirow[t]{2}{*}{$P$ value } \\
\hline & $\mathrm{N}$ & $\%$ & N & $\%$ & & Mean & SD & Mean & SD & \\
\hline \multicolumn{11}{|l|}{ Mania Symptom Index } \\
\hline Extremely energetic/active & 32 & 34.8 & 11 & 39.3 & 0.66 & 8 & 5.8 & 4.9 & 3.6 & 0.10 \\
\hline Overly cheerful, happy, on top of the world & 27 & 29.4 & 8 & 28.6 & 0.94 & 13.9 & 21.1 & 8.6 & 8.6 & 0.38 \\
\hline Racing thoughts & 24 & 26.1 & 6 & 21.4 & 0.62 & 8.3 & 6.7 & 4.3 & 3.5 & 0.24 \\
\hline Overly talkative & 32 & 34.8 & 9 & 32.1 & 0.80 & 6.5 & 4 & 8.6 & 8.6 & 0.82 \\
\hline Decreased need for sleep & 18 & 19.6 & 5 & 17.9 & 0.84 & 13.7 & 28.5 & 5.2 & 4.7 & 0.45 \\
\hline Irritability or anger & 21 & 22.8 & 6 & 21.4 & 0.88 & 15.8 & 25.4 & 7.2 & 5.2 & 0.54 \\
\hline Overly self-confident & 13 & 14.1 & 3 & 10.7 & 0.64 & 21.6 & 50.3 & 15.6 & 20.9 & 0.53 \\
\hline Physical agitated & 9 & 9.8 & 3 & 10.7 & 0.89 & 13 & 9.7 & 6.1 & 4.9 & 0.18 \\
\hline Increased sexual energy & 3 & 3.3 & 3 & 10.7 & 0.14 & 5.8 & 3.5 & 6.5 & 7.5 & 0.74 \\
\hline Reckless or dangerous behaviors & 10 & 10.9 & 3 & 10.7 & $1.00^{\mathrm{a}}$ & 21.6 & 40.4 & 10.1 & 10.9 & 0.90 \\
\hline Risky sexual behavior & 3 & 3.3 & 3 & 10.7 & $0.14^{a}$ & 2.2 & 3.1 & 10.8 & 15.3 & 0.68 \\
\hline Trouble concentrating & 14 & 15.2 & 4 & 14.3 & $1.00^{\mathrm{a}}$ & 17.3 & 14 & 8.6 & 6.1 & 0.22 \\
\hline Mania Index total & 65 & 70.7 & 18 & 64.3 & 0.52 & 15.8 & 28.6 & 12.2 & 13.8 & 0.83 \\
\hline \multicolumn{11}{|l|}{ Depression Symptom Index } \\
\hline Depressed mood & 7 & 7.6 & 4 & 14.3 & $0.28^{\mathrm{a}}$ & 30.8 & 36.7 & 10.4 & 4.9 & 0.37 \\
\hline Tiredness or lack of energy & 6 & 6.5 & 2 & 7.1 & $1.00^{\mathrm{a}}$ & 15.6 & 12.4 & 8.6 & 4.3 & 0.55 \\
\hline Reduction of enjoyment/ interest & 6 & 6.5 & 1 & 3.6 & $1.00^{\mathrm{a}}$ & 25.2 & 22.1 & 4.3 & 6.1 & 0.18 \\
\hline Trouble concentrating & 14 & 15.2 & 4 & 14.3 & $1.00^{\mathrm{a}}$ & 17.3 & 14 & 8.6 & 6.1 & 0.22 \\
\hline Insomnia & 18 & 19.6 & 3 & 10.7 & $0.40^{\mathrm{a}}$ & 11.7 & 12.5 & 5.8 & 6.6 & 0.35 \\
\hline Feeling of worthless or guilty & 5 & 5.4 & 2 & 7.1 & $0.66^{\mathrm{a}}$ & 10.4 & 10.8 & 6.5 & 2.5 & 1.00 \\
\hline Weight loss or decrease in appetite & 5 & 5.4 & 3 & 10.7 & $0.39^{a}$ & 17.3 & 21.8 & 8.6 & 5.3 & 0.91 \\
\hline Physically slowed down & 3 & 3.3 & 0 & 0.0 & $1.00^{a}$ & 18.7 & 28.8 & - & - & n.a. \\
\hline Thinking about suicide & 1 & 1.1 & 1 & 3.6 & $0.41^{\mathrm{a}}$ & 10.1 & 13.9 & 4.3 & 6.1 & 0.77 \\
\hline Sleeping too much & 5 & 5.4 & 1 & 3.6 & $1.00^{\mathrm{a}}$ & 30.3 & 49 & 10.1 & 13.9 & 0.46 \\
\hline Attempting suicide & 1 & 1.1 & 0 & 0.0 & $1.00^{\mathrm{a}}$ & 2.2 & 3.1 & - & - & n.a. \\
\hline Weight gain or increasing in appetite & 5 & 5.4 & 4 & 14.3 & 0.21 & 16.2 & 24 & 16.2 & 24 & 1.00 \\
\hline Depression Index Total & 33 & 35.9 & 12 & 42.9 & 0.50 & 20.3 & 28.1 & 14.4 & 14.7 & 0.95 \\
\hline \multicolumn{11}{|l|}{ General Symptom Index } \\
\hline Educational and occupational dysfunction & 20 & 21.7 & 2 & 7.1 & 0.081 & 18.5 & 15.6 & 8.6 & 6.1 & 0.37 \\
\hline Anxiety or nervousness & 16 & 17.4 & 5 & 17.9 & $1.00^{\mathrm{a}}$ & 38.9 & 50.6 & 13.8 & 16.8 & 0.23 \\
\hline Social isolation & 12 & 13.0 & 1 & 3.6 & $0.30^{\mathrm{a}}$ & 21.2 & 17.9 & 6.9 & 3.9 & 0.078 \\
\hline Frequent mood swings/lability & 28 & 30.4 & 6 & 21.4 & 0.35 & 17.7 & 29.9 & 11.7 & 11.4 & 0.86 \\
\hline Difficulty making decisions & 4 & 4.4 & 3 & 10.7 & $0.35^{\mathrm{a}}$ & 31.3 & 48.4 & 6.1 & 3.9 & 0.45 \\
\hline Obsessions and compulsions & 7 & 7.6 & 2 & 7.1 & $1.00^{\mathrm{a}}$ & 26.5 & 39.7 & 6.5 & 5.6 & 0.44 \\
\hline Losing temper frequently or trouble controlling anger & 30 & 32.6 & 4 & 14.3 & 0.060 & 12.3 & 23.6 & 7.2 & 4.3 & 0.83 \\
\hline Day/night sleep reversal & 5 & 5.4 & 1 & 3.6 & $1.00 \mathrm{a}$ & 11.7 & 17.9 & 10.1 & 13.9 & 0.72 \\
\hline Self-injurious behavior (no intent to kill self) & 0 & 0.0 & 0 & 0.0 & n.a & 79.9 & 106.9 & 4.3 & 6.1 & 0.44 \\
\hline Oppositionality & 15 & 16.3 & 3 & 10.7 & $0.58^{\mathrm{a}}$ & 22.6 & 31.1 & 5.8 & 6.6 & 0.13 \\
\hline Giddy, clownish & 15 & 16.3 & 3 & 10.7 & $0.56^{\mathrm{a}}$ & 10.8 & 14.9 & 7.2 & 6.6 & 0.93 \\
\hline Increased creativity & 12 & 13.0 & 5 & 17.9 & $0.54^{\mathrm{a}}$ & 21.1 & 50.5 & 12.1 & 17.7 & 0.82 \\
\hline
\end{tabular}


Table 3 Reported Prevalence and Duration of Prodromal Symptoms Between Patients with BD-I and BD-II Prior to the First Mania/ Hypomania Episode (Continued)

\begin{tabular}{|c|c|c|c|c|c|c|c|c|c|c|}
\hline \multirow{3}{*}{$\begin{array}{l}\text { Prodromal symptom characteristics } \\
\text { VGeneral Index Total }\end{array}$} & \multicolumn{5}{|c|}{ Prevalence (Yes/No) } & \multicolumn{5}{|c|}{ Duration (Weeks) } \\
\hline & \multicolumn{2}{|c|}{$\mathrm{BD}-\mathrm{I}(n=92)$} & \multicolumn{2}{|c|}{$\mathrm{BD}-\mathrm{II}(n=28)$} & \multirow{2}{*}{$\frac{\mathbf{P} \text { value }}{0.51}$} & \multicolumn{2}{|c|}{$\mathrm{BD}-\mathrm{I}(n=92)$} & \multicolumn{2}{|c|}{$\mathrm{BD}-\mathrm{II}(n=28)$} & \multirow{2}{*}{$\frac{P \text { value }}{0.70}$} \\
\hline & 62 & 67.4 & 17 & 60.7 & & 20.1 & 35.6 & 14.5 & 14.4 & \\
\hline \multicolumn{11}{|l|}{ Psychosis Symptom Index } \\
\hline Suspiciousness/persecutory ideas & 20 & 21.7 & 4 & 14.3 & 0.39 & 13.9 & 26.3 & 4.3 & 3.1 & 0.22 \\
\hline Strange or unusual ideas & 21 & 22.8 & 4 & 14.3 & 0.33 & 20.7 & 30 & 5.8 & 5 & 0.23 \\
\hline Difficulty thinking or communicating clearly & 9 & 9.8 & 3 & 10.7 & $1.00^{\mathrm{a}}$ & 18 & 17.2 & 0 & & n.a. \\
\hline Hallucinations & 5 & 5.4 & 1 & 3.6 & $1.00 \mathrm{a}$ & 10.1 & 9 & 2.2 & 3.1 & 0.37 \\
\hline Psychosis Index Total & 32 & 34.8 & 7 & 25.0 & 0.33 & 16.8 & 24.7 & 5.0 & 3.3 & 0.11 \\
\hline BPSS-R Total & 75 & 81.5 & 22 & 78.6 & 0.73 & 18.4 & 32.6 & 15.7 & 15.0 & 0.48 \\
\hline
\end{tabular}

Abbreviations: BD, Bipolar Disorder; SD, Standard Deviation; BPSS-R, Bipolar Prodrome Symptom Scale-Retrospective

n.a. $=$ not applicable

${ }^{*} P<0.05 * * P<0.01{ }^{* * *} P<0.001$

a: Fisher exact test

$0.001)$, difficulty making decisions $(p=0.0012)$, oppositionality $(p=0.012)$, and suspiciousness/persecutory ideas $(p=0.017)$ than those reported in BD- I. There were also differences in the duration of the precursors. The duration of "weight loss or decrease in appetite" $(p=0.016)$ lasted longer in patients with BD-I, while "obsessions and compulsions" $(p=0.023)$ started earlier in patients with BD-II in the pre-depressive period. The prevalence and duration of each reported prodrome preceding a first (hypo) mania episode showed no difference between patients with BD-I and BD-II.

In this study, for the first depressive episode, patients with BD-II had more prodromes in each subdomain than patients with BD-I. BD-II patients had more occurrences of educational and occupational dysfunction, social isolation, difficulty making decisions, oppositionality, and suspiciousness/persecutory ideas before the first full-blown depressive episode. The patients also revealed a history of subsyndromal depressive symptoms, which were predictors for $\mathrm{BD}$, which is further supported by a previous study [31]. BD-II has been established to be more severe and challenging compared to BD-I in several studies, such as higher rates of early onset, longer BD duration, higher prevalence of psychiatric comorbidity, more prior mood episodes, as well as more current depressive symptoms $[24,32]$. This study's findings indicate that having a substantial subthreshold for depressive symptoms entails a greater potential of development of BD-II. Indeed, improved knowledge of prodromal symptoms for BD-II could help identify the disorder earlier and facilitate enhanced treatment for such individuals.

A history of mood swings/lability prior to the a first (hypo) manic episode was reported by more than a quarter of patients in this study, with a larger proportion in BD-I patients compared to BD-II patients (30.4\% vs.
21.4\%). This is consistent with previous studies that mood swings/lability can represent a precursor or part of a prodrome evolving into a full (hypo) maniac episode both in youth and adults [33, 34]. Previous studies have also found that lifetime subsyndromal hypomanic symptoms predicted later development of $\mathrm{BD}$ spectrum disorders $[19,35,36]$. This study confirmed that subsyndromal hypomania, such as "extremely energetic/active", "overly cheerful, happy, on top of the world", "racing thoughts", and "overly talkative" was reported as pre-(hypo) manic symptoms by most of the patients. It is worth noting that $28.6 \%$ of $\mathrm{BD}-\mathrm{II}$ patients in this study reported attenuated mania-like symptoms before full expression of a depressive episode, and that previous studies further supported that depression as associated with hypomanic features increased the risk of later $\mathrm{BD}[37,38]$.

Anxiety symptoms, psychotic features, and other nonspecific psychopathological presentations emerged as antecedents to the onset of BD in several studies $[11,13$, $39-41]$. As this study presented, anxiety or nervousness was common in the prodromal stage in both BD-I and BD-II patients. In addition, in this study BD-II patients presented more general symptoms compared to BD-I patients, prior to a first depressive episode, including "educational and occupational dysfunction", "social isolation", "difficulty making decisions" and "oppositionality". These nonspecific symptoms are worthy of attention in future clinical work as theymay be relatively sensitive in predicting later onset of BD-II. Psychotic features have also been identified as clinical precursors of BD and have indicated the progression of $\mathrm{BD}$ conversion in the clinical phases [40, 41]. In this study, it is interesting to note that BD-II patients reported more psychotic symptoms before the first depressive episode, which extends the 
understanding of characteristics of prodromes of BD-II. It further confirmed that there exists a substantial burden of the various dimensional symptoms in BD-II.

In this study, the prodromal symptoms persisted for a period prior to the first affective episode. Several studies confirm the progressive nature of BD. The duration of prodromes was relatively shorter in our study (2-32 weeks, with most lasting 10-15 weeks), compared with those in previous studies [22, 35, 42, 43]. A metaanalysis reported that the average duration of the prodromal period preceding an initial mood episode (manic or depressive) was $107.9 \pm 91.5$ months, although the average prodrome duration to an initial manic episode was $10.6 \pm 10.9$ months, which is obviously shorter than the average duration considering both depressive and maniac episodes [43]. In this study, the data set of participants was smaller. Therefore the researchers speculated that there were several potential relative reasons for the differences between the studies' findings. Firstly, many patients with BD-I reported an initial manic episode in this study. Therefore, bias in sample composition may have had an impact on the results. Secondly, quite a few people in China lack knowledge about mental disorders, which limits their ability to recognize early symptoms. Thirdly, due to the reserved culture, Chinese people might be more prone to suppress their inner emotions. Fourthly, recall bias might exist in a retrospective study, which is mainly based on patients' subjective report, even if the course of the disorder was limited to within 3 years of onset. Despite this, the duration of the prodromes could provide clinicians a chance to conduct earlier interventions. Notably, in this study "Weight loss or decrease in appetite" and "obsessions and compulsions" started earlier in BD-II patients preceding a first depressive episode. Previous studies reported that individuals with obsessive-compulsive disorder had a 13-fold increased risk of developing BD [37], and obsessive and compulsive symptoms were more common in BD- II than in BD-I [44], indicating that the presence of obsessive-compulsive disorder may be an independent risk factor for the later development of $\mathrm{BD}$, especially for BD- II.

There are several limitations to our study. First, the study was based on a mixed sample of patients with BDI and BD-II. The sample size was relatively small, which might limit the generalization of the findings. However, in a recent large-scare epidemiological study of mental disorders in China [45], the life-time prevalence of BD-I and BD-II were $0.4 \%(106 / 32552)$ and less than $0.1 \%$ $(12 / 32552)$ respectively. The prevalence of BD-I is then considered to be 8 times more than BD-II in China, consistent with this study in which more BD-I patients than BD-II patients were enrolled. Our study also focused on the comparison of prodromal symptoms, which are relatively common in BD patients. Some specific features for each subtype of BD were detected in this study, although the small sample size was not adequately powered to detect differences with small effect sizes. Secondly, although the retrospective cross-sectional design of this study might cause recall bias; the researchers did restrict the course of the disorder within three years of onset, which could decrease the recall bias. Thirdly, family history of mental disorder(s) was not collected in this study, which could be an important predictive factor to characterize prodromal symptoms. Another limitation is that patients with borderline personality disorder may not have been picked up during the screening process. Although open questions about personality and extreme behavior were asked to patients and their family members to exclude potential individuals with personality disorders, this was a rough screening. The Structured Clinical Interview for DSM-IV Axis II Disorders should be used to identify borderline personality disorder in the future.

In addition, the researchers used standardized diagnostic tools and semi-fixed assessment tools to diagnose and evaluate patients, but failed to set up a control group, such as monophasic depression, schizophrenia, and healthy controls. Including control groups would improve rigor, as prodromal symptoms may overlap between different disorders and also occur in normal populations. Some prospective studies have assessed mood symptoms in healthy individuals. A study with college students who had "subsyndromal bipolar" were more likely to develop BD or major depressive disorder [46]. A dose-response relationship between the number of both manic and depressive symptoms and persistence was observed in adolescents and young adults [47]. In bipolar offspring in the study, an individual risk calculator was developed to predict the 5-year risk of developing $\mathrm{BD}$ [34]. In non-BD individuals a lower incidence of prodromal symptoms and shorter duration of symptoms was found. Overall, the prodromal symptoms had a predictive effect on $\mathrm{BD}$.

\section{Conclusions}

In conclusion, specific affective symptoms, as well as general or psychotic symptoms, occurred prior to both affective episodes in BD. Characteristics of prodromal symptoms included attenuated mania-like symptoms, subthreshold depressed mood, mood swings/lability, and anxiety were key predictors for later onset of BD. In non-specific dimensions, the pre-depressive state presented more prodromal symptoms in BD-II compared to $\mathrm{BD}-\mathrm{I}$, indicating the substantial disorder burden of BDII. Overall, this study extended the understanding of characteristics of prodromes of BD-I and BD-II. 


\section{Abbreviations}

BD: Bipolar disorder; BPSS-R: The Bipolar Prodrome Symptom ScaleRetrospective; SCID: Structured Clinical Interview for Diagnostic and Statistical Manual (DSM)-IV-TR axis 1 disorders; HAMD-17: The Hamilton depression scale-17; YMRS: The Young Mania Rating Scale; SD: Standard deviation

\section{Supplementary Information}

The online version contains supplementary material available at https://doi. org/10.1186/s12888-021-03295-y.

Additional file 1.

\section{Acknowledgements}

We thank the clinicians and patients involved in this study. We acknowledge Professor Christoph U Correll, from the Zucker Hillside Hospital, Psychiatry Research, Glen Oaks, NY 11004, USA; Charité Universitätsmedizin Berlin, Department of Child and Adolescent Psychiatry, Berlin, Germany for his guidance of the BPSS-R and acknowledge Tam Man lan, MPhil, from the Department of Psychiatry, Conde de São Januário, General Hospital of Macau, for the back translation of the BPSS.

\section{Authors' contributions}

All authors provided final approval of the submitted manuscript. QZ was responsible for methodology, data collection and writing the original draft; TG was involved in methodology, data collection and project administration; LY and LZ were responsible for methodology and data collection; AW was responsible for writing-review and editing; NL was responsible for writing original draft; XZ was involved in data analysis; XL was responsible for methodology, supervision, writing-review, editing and funding acquisition.

\section{Funding}

The study was supported by the National Key Research \& Development Program of China (No. 2016YFC1307200), Capital City Clinical Practice and Research Funding of Beijing Municipal Science \& Technology Commission (Z151100004015042), and Beijing Municipal Science \& Technology Commission (No. Z181100001718124).

\section{Availability of data and materials}

The datasets generated and analyzed during the current study are not publicly available due to ethical restrictions and personal data protection, but are available from the corresponding author Dr. Xiaohong Li on reasonable request.

\section{Declarations}

\section{Ethics approval and consent to participate}

This study was approved by the Ethics Committee of Beijing Anding Hospital Capital Medical University (No. 2015-126). All methods were performed in accordance with the relevant guidelines of IGH-GCP and law of China. All subjects understood the purpose and procedure of the study and provided informed written consent prior to enrollment. They were aware they could withdraw their data at any point.

\section{Consent for publication}

Not applicable.

\section{Competing interests}

The authors declare that they have no competing interests.

\section{Author details}

'The National Clinical Research Center for Mental Disorders \& Beijing Key Laboratory of Mental Disorders, Beijing Anding Hospital, Capital Medical University, Beijing, China. ${ }^{2}$ Beijing Advanced Innovation Center for Big Data Based Precision Medicine, Beihang University, Beijing, China. ${ }^{3}$ Division of Psychology, Faculty of Health and Life Sciences, De Montfort University, Leicester, UK.
Received: 2 February 2021 Accepted: 11 May 2021

Published online: 31 May 2021

\section{References}

1. Martin DJ, Smith DJ. Is there a clinical prodrome of bipolar disorder? A review of the evidence. Expert Rev Neurother. 2013;13(1):89-98. https://doi. org/10.1586/ern.12.149.

2. Bauer M, Andreassen OA, Geddes JR, Vedel Kessing L, Lewitzka U, Schulze TG, Vieta E Areas of uncertainties and unmet needs in bipolar disorders: clinical and research perspectives. Lancet Psychiatry 2018.5: 930-939. https://doi.org/10.1016/s2215-0366(18)30253-0, 11.

3. Phillips ML, Kupfer DJ Bipolar disorder diagnosis: challenges and future directions. Lancet. 2013.381: 1663-1671. https://doi.org/10.1016/s0140-673 6(13)60989-7, 9878.

4. Grande I, Berk M, Birmaher B, Vieta E. Bipolar disorder. Lancet. 2016.387: 1561-1572. https://doi.org/10.1016/s0140-6736(15)00241-x, 10027.

5. Berk M, Berk L, Dodd S, Cotton S, Macneil C, Daglas R, et al. Stage managing bipolar disorder. Bipolar Disord. 2014;16(5):471-7. https://doi. org/10.1111/bdi.12099.

6. Kapczinski NS, Mwangi B, Cassidy RM, Librenza-Garcia D, Bermudez MB, Kauer-Sant'anna M, et al. Neuroprogression and illness trajectories in bipolar disorder. Expert Rev Neurother. 2017;17(3):277-85. https://doi.org/10.1 080/14737175.2017.1240615.

7. Baldessarini RJ, Bolzani L, Cruz N, Jones PB, Lai M, Lepri B, et al. Onset-age of bipolar disorders at six international sites. J Affect Disord. 2010;121(1-2):1436. https://doi.org/10.1016/.j.jad.2009.05.030.

8. Vieta E, Salagre E, Grande I, Carvalho AF, Fernandes BS, Berk M, et al. Early intervention in bipolar disorder. Am J Psychiatry. 2018;175(5):411-26. https:// doi.org/10.1176/appi.ajp.2017.17090972

9. Goi PD, Bücker J, Vianna-Sulzbach M, Rosa AR, Grande I, Chendo I, et al. Pharmacological treatment and staging in bipolar disorder: evidence from clinical practice. Braz J Psychiatry. 2015;37(2):121-5. https://doi.org/10.1590/1 516-4446-2014-1554

10. Tohen M, Vieta E, Gonzalez-Pinto A, Reed C, Lin D, European Mania in Bipolar Longitudinal Evaluation of Medication (EMBLEM) Advisory Board. Baseline characteristics and outcomes in patients with first episode or multiple episodes of acute mania. J Clin Psychiatry. 2010;71(03):255-61. https://doi.org/10.4088/JCP.08m04580.

11. Axelson D, Goldstein B, Goldstein T, Monk K, Yu H, Hickey MB, et al. Diagnostic precursors to bipolar disorder in offspring of parents with bipolar disorder: a longitudinal study. Am J Psychiatry. 2015;172(7):638-46. https://doi.org/10.1176/appi.ajp.2014.14010035.

12. Hafeman DM, Merranko J, Axelson D, Goldstein BI, Goldstein T, Monk K, et al. Toward the definition of a bipolar Prodrome: dimensional predictors of bipolar Spectrum disorders in at-risk youths. Am J Psychiatry. 2016;173(7): 695-704. https://doi.org/10.1176/appi.ajp.2015.15040414.

13. Mesman E, Nolen WA, Keijsers L, Hillegers MHJ. Baseline dimensional psychopathology and future mood disorder onset: findings from the Dutch bipolar offspring study. Acta Psychiatr Scand. 2017;136(2):201-9. https://doi. org/10.1111/acps.12739.

14. Preisig M, Strippoli MF, Castelao E, et al. The specificity of the familial aggregation of early-onset bipolar disorder: a controlled 10-year follow-up study of offspring of parents with mood disorders. J Affect Disord. 2016;190: 26-33. https://doi.org/10.1016/j.jad.2015.10.005.

15. Østergaard SD, Straszek S, Petrides G, Skadhede S, Jensen SOW, MunkJørgensen $\mathrm{P}$, et al. Risk factors for conversion from unipolar psychotic depression to bipolar disorder. Bipolar Disord. 2014;16(2):180-9. https://doi. org/10.1111/bdi.12152.

16. Ratheesh A, Davey C, Hetrick S, Alvarez-Jimenez M, Voutier C, Bechdolf A, et al. A systematic review and meta-analysis of prospective transition from major depression to bipolar disorder. Acta Psychiatr Scand. 2017;135(4):27384. https://doi.org/10.1111/acps.12686.

17. Post RM, Altshuler LL, Kupka R, McElroy SL, Frye MA, Rowe M, et al. Age of onset of bipolar disorder: combined effect of childhood adversity and familial loading of psychiatric disorders. J Psychiatr Res. 2016;81:63-70. https://doi.org/10.1016/j.jpsychires.2016.06.008.

18. Jiménez E, Brisa Solé B, Arias B, et al. Impact of childhood trauma on cognitive profile in bipolar disorder. Bipolar Disord. 2017;19(5):363-74. https://doi.org/10.1111/bdi.12514.

19. Ratheesh A, Cotton SM, Betts JK, Chanen A, Nelson B, Davey CG, et al. Prospective progression from high-prevalence disorders to bipolar disorder: 
exploring characteristics of pre-illness stages. J Affect Disord. 2015;183:45-8. https://doi.org/10.1016/j.jad.2015.04.025.

20. Correll CU, Penzner JB, Frederickson AM, Richter JJ, Auther AM, Smith CW, et al. Differentiation in the preonset phases of schizophrenia and mood disorders: evidence in support of a bipolar mania prodrome. Schizophr Bull. 2007:33(3):703-14. https://doi.org/10.1093/schbul/sbm028.

21. Zeschel E, Correll CU, Haussleiter IS, Krüger-Özgürdal S, Leopold K, Pfennig A, et al. The bipolar disorder prodrome revisited: is there a symptomatic pattern? J Affect Disord. 2013;151(2):551-60. https://doi.org/10.1016/j.jad.2 013.06.043.

22. Correll CU, Hauser M, Penzner JB, Auther AM, Kafantaris V, Saito E, et al. Type and duration of subsyndromal symptoms in youth with bipolar I disorder prior to their first manic episode. Bipolar Disord. 2014;16(5):478-92. https://doi.org/10.1111/bdi.12194.

23. Zeschel E, Bingmann T, Bechdolf A, Krüger-Oezquerdal S, Correll CU, Leopold $\mathrm{K}$, et al. Temperament and prodromal symptoms prior to first manic/hypomanic episodes: results from a pilot study. J Affect Disord. 2015; 173:39-44. https://doi.org/10.1016/j.jad.2014.10.031.

24. Karanti A, Kardell M, Joas E, Runeson B, Pålsson E, Landén M. Characteristics of bipolar I and II disorder: a study of 8766 individuals. Bipolar Disord. 2020; 22(4):392-400. https://doi.org/10.1111/bdi.12867.

25. Judd LL, Akiskal HS, Schettler PJ, Coryell W, Maser J, Rice JA, Solomon DA, Keller MB The comparative clinical phenotype and long term longitudinal episode course of bipolar I and II: a clinical spectrum or distinct disorders? J Affect Disord 2003.73: 19-32. https://doi.org/10.1016/s0165-0327(02)00324-5, 1-2.

26. Judd LL, Schettler PJ, Akiskal HS, Maser J, Coryell W, Solomon D, et al. Longterm symptomatic status of bipolar I vs. bipolar II disorders. Int J Neuropsychopharmacol. 2003;6(2):127-37. https://doi.org/10.1017/s146114 5703003341

27. First MB, Spitzer RL, Gibbon M, JBW W. Structured Clinical Interview for DSM-IV-TR Axis I Disorders, Research Version, Patient Edition (SCID-I/P). New York: Biometrics Research Department, New York State Psychiatric Institute; 2001.

28. Hamilton M. A rating scale for depression. J Neurol Neurosurg Psychiatry. 1960;23(1):56-62. https://doi.org/10.1136/jnnp.23.1.56.

29. Zheng YP, Zhao JP, Phillips M, Liu J, Cai M, Sun S, et al. Validity and reliability of the Chinese Hamilton depression rating scale. Br J Psychiatry. 1988:152(5):660-4. https://doi.org/10.1192/bjp.152.5.660.

30. Young RC, Biggs JT, Ziegler VE, Meyer DA. A rating scale for mania: reliability, validity and sensitivity. Br J Psychiatry. 1978;133(5):429-35. https:// doi.org/10.1192/bjp.133.5.429.

31. Regeer EJ, Krabbendam L, de Graaf R, et al. A prospective study of the transition rates of subthreshold (hypo) mania and depression in the general population. Psychol Med. 2006;36(05):619-27. https://doi.org/10.1017/s00332 91705006823

32. Dell'Osso B, Holtzman JN, Goffin KC, et al. American tertiary clinic-referred bipolar II disorder compared to bipolar I disorder: more severe in multiple ways, but less severe in a few other ways. J Affect Disord. 2015;188:257-62. https://doi.org/10.1016/j.jad.2015.09.001.

33. Faedda GL, Baldessarini RJ, Glovinsky IP, Austin NB. Pediatric bipolar disorder: phenomenology and course of illness. Bipolar Disord. 2004;6(4): 305-13. https://doi.org/10.1111/j.1399-5618.2004.00128.x.

34. Hafeman DM, Merranko J, Goldstein TR, Axelson D, Goldstein Bl, Monk K, et al. Assessment of a person-level risk calculator to predict new-onset bipolar Spectrum disorder in youth at familial risk. JAMA Psychiatry. 2017; 74(8):841-7. https://doi.org/10.1001/jamapsychiatry.2017.1763.

35. Boschloo L, Spijker AT, Hoencamp E, Kupka R, Nolen WA, Schoevers RA, et al. Predictors of the onset of manic symptoms and a (hypo) manic episode in patients with major depressive disorder. PLoS One. 2014;9(9): e106871. https://doi.org/10.1371/journal.pone.0106871.

36. Papachristou E, Oldehinkel AJ, Ormel J, Raven D, Hartman CA, Frangou S, et al. The predictive value of childhood subthreshold manic symptoms for adolescent and adult psychiatric outcomes. J Affect Disord. 2017;212:86-92. https://doi.org/10.1016/j.jad.2017.01.038

37. Cederlöf $M$, Lichtenstein $P$, Larsson $H$, Boman $M$, Rück $C$, Landén $M$, et al. Obsessive-compulsive disorder, psychosis, and bipolarity: a longitudinal cohort and multigenerational family study. Schizophr Bull. 2015;41(5):107683. https://doi.org/10.1093/schbul/sbu169.

38. Nadkarni RB, Fristad MA. Clinical course of children with a depressive spectrum disorder and transient manic symptoms. Bipolar Disord. 2010; 12(5):494-503. https://doi.org/10.1111/j.1399-5618.2010.00847.x.
39. Duffy A, Horrocks J, Doucette S, Keown-Stoneman C, McCloskey S, Grof P. Childhood anxiety: an early predictor of mood disorders in offspring of bipolar parents. J Affect Disord. 2013;150(2):363-9. https://doi.org/10.1016/j. jad.2013.04.021.

40. Salvatore P, Baldessarini RJ, Khalsa HM, et al. Antecedents of manic versus other first psychotic episodes in 263 bipolar I disorder patients. Acta Psychiatr Scand. 2014;129(4):275-85. https://doi.org/10.1111/acps.12170.

41. Tohen M, Khalsa HK, Salvatore P, et al. Two-year outcomes in first-episode psychotic depression the McLean-Harvard First-episode project. J Affect Disord. 2012;136(1-2):1-8. https://doi.org/10.1016/j.jad.2011.08.028.

42. Bechdolf A, Nelson B, Cotton SM, Chanen A, Thompson A, Kettle J, et al. A preliminary evaluation of the validity of at-risk criteria for bipolar disorders in help-seeking adolescents and young adults. J Affect Disord. 2010;127(1-3): 316-20. https://doi.org/10.1016/j.jad.2010.06.016.

43. Van Meter AR, Burke C, Youngstrom EA, et al. The bipolar Prodrome: metaanalysis of symptom prevalence prior to initial or recurrent mood episodes. J Am Acad Child Adolesc Psychiatry. 2016;55(7):543-55. https://doi.org/10.1 016/j.jaac.2016.04.017.

44. Perugi G, Akiskal HS, Gemignani A, Pfanner C, Presta S, Milanfranchi A, et al. Episodic course in obsessive-compulsive disorder. Eur Arch Psychiatry Clin Neurosci. 1998;248(5):240-4. https://doi.org/10.1007/s004060050044.

45. Huang Y, Wang Y, Wang H, Liu Z, Yu X, Yan J, Yu Y, Kou C, Xu X, Lu J, Wang Z, He S, Xu Y, He Y, Li T, Guo W, Tian H, Xu G, Xu X, Ma Y, Wang L, Wang L, Yan Y, Wang B, Xiao S, Zhou L, Li L, Tan L, Zhang T, Ma C, Li Q, Ding H, Geng H, Jia F, Shi J, Wang S, Zhang N, du X, du X, Wu Y Prevalence of mental disorders in China: a cross-sectional epidemiological study. Lancet Psychiatry 2019.6: 211224. https://doi.org/10.1016/s2215-0366(18)30511-x, 3.

46. Lewinsohn PM, Klein DN. Seeley JR bipolar disorder during adolescence and young adulthood in a community sample. Bipolar Disord. 2000;2(3p2):28193. https://doi.org/10.1034/j.1399-5618.2000.20309.x.

47. Tijssen MJ, Van Os J, Wittchen HU, et al. Risk factors predicting onset and persistence of subthreshold expression of bipolar psychopathology among youth from the community. Acta Psychiatr Scand. 2010;122(3):255-66. https://doi.org/10.1111/j.1600-0447.2010.01539.x.

\section{Publisher's Note}

Springer Nature remains neutral with regard to jurisdictional claims in published maps and institutional affiliations.

Ready to submit your research? Choose BMC and benefit from:

- fast, convenient online submission

- thorough peer review by experienced researchers in your field

- rapid publication on acceptance

- support for research data, including large and complex data types

- gold Open Access which fosters wider collaboration and increased citations

- maximum visibility for your research: over $100 \mathrm{M}$ website views per year

At BMC, research is always in progress.

Learn more biomedcentral.com/submissions 